\title{
Steel quality of rolling contact bearings produced by different manufacturers, used for mining equipment instrumentation
}

\author{
Aleksandr Korotkov $^{1 *}$, Lidiya Korotkova ${ }^{1}$, Stefan Voeth, and Roman Solentsov ${ }^{2}$ \\ ${ }^{1}$ T.F. Gorbachev Kuzbass State Technical University, Metal-Cutting Machines and Tools \\ Department, 28 Vesennyaya Street, the City of Kemerovo, the Russian Federation, 650000 \\ ${ }^{2}$ Ministry of Industry of Kuzbass, 63 Sovetskiy Avenue, the City of Kemerovo, the Russian \\ Federation, 650000
}

\begin{abstract}
Severe operating conditions of mining equipment have a negative impact on the operating life of the rolling contact bearings used in such equipment. The main reasons for the premature failure of rolling contact bearings include, first of all, poor quality of the bearing steel as delivered and the defects of their subsequent heat treatment. The abovementioned reasons result in splitting of bearings, metal shelling and appearance of potholes on their tracks, as well as intense abrasive wear. Nevertheless, despite the importance of this issue, the quality of bearing steel, either as delivered or in finished bearings, is usually not under control.To solve this problem, the quality of bearing steel was studied, exemplified by the bearings of the Russian, Swedish (SKF) and Japanese (NSK) manufacturers, i.e., main suppliers of rolling contact bearings for mining equipment in Russia. The problem of bearing steel quality control was solved by developing a quality control methodology that took into account the state of the metal after metallurgical treatment and at the stage of bearing production. Based on this methodology, the main types of bearing steel defects affecting the mechanism of bearing failure are identified.It is found that the bearing steel quality of domestic manufacturers is highly competitive with foreign counterparts. A method of nondestructive control is also proposed for detecting possible microstructure defects in bearings, either as delivered or while in operation.
\end{abstract}

\section{Relevance of Study}

The efficiency of the mining equipment operation is interrelated with the quality of the bearings used. The service life of the equipment depends on the quality of the bearings and it affects the working cost of the final product, being an indicator of the mining industry competitiveness [1,2].

It is known that the quality of bearings is formed at various technological stages and

\footnotetext{
* Corresponding author: korotkovan@kuzstu.ru
} 
depends on the following components:

- thoroughness and accuracy of the manufacturing technology, including metallurgical and blank production, as well as mechanical processing;

- bearing materials quality;

- assembling accuracy of bearings [3].

Quality control of bearings can be carried out as delivered and while in operation. Currently, the following types of bearing control are used - visual control with external inspection and verification of marking, control of ease of rotation and intensity of noise, as well as control of overall dimensions, radial clearances, and vibration parameters [4].

Many enterprises do not carry out quality control of the bearing metal, notwithstanding the fact that their performance depends greatly on this parameter. Therefore, the task was set to study the quality of the bearing steel as delivered and to identify possible defects in finished bearings of various manufacturers.

\section{Research Method}

Bearing steel includes such steel grades as ShKh4, ShKh15, ShKh15S [5]. Their wear resistance is ensured by the chemical composition, namely high carbon content, as well as by heat treatment in order to form a martensitic structure with the $60 \div 62 \mathrm{HRC}$ hardness. The fatigue strength of such steel grades is ensured due to increased requirements for their quality. Bearing steel is intended for the manufacture of machine parts and mechanisms that are capable of operating under conditions of intense abrasive and fatigue wear, as well as under conditions of high contact pressures and shock loads. Therefore, it is subject to increased requirements concerning fatigue strength and wear resistance. Bearing steel is used for the manufacture of inner and outer rings, balls and rollers of rolling contact bearings.

The paper uses the method of quality control of bearing steels, developed at the MetalCutting Machines and Tools Department of Kuzbass State Technical University, which is based on the current standards [6]. In this case, the quality control of bearing steel is carried out on the basis of the developed quality control methodology, which takes into account the state of the metal after metallurgical treatment and at the stage of bearing production. This technique is based on taking into account the parameters of the structure and properties that must be provided to the steel as delivered and at the stage of hardening heat treatment in accordance with the current standards [7]. The standard includes the following control parameters:

- presence of defects (GOST 801);

- linear dimensions and configuration (GOST 6507 or GOST 4381);

- chemical composition (GOST 54153);

- mechanical properties (GOST 9012, GOST 9013);

- macro- and microstructure (GOST 10243, GOST 801).

The control of the microstructure of bearing steels is carried out according to the following parameters - decarburized layer, microstructure of pearlite, presence of residues of a carbide network and carbide segregation, structural banding, presence of non-metallic inclusions, and microporosity.

\section{Results of Study}

Mining equipment is instrumented with bearings of not only Russian manufacturers but also the foreign ones, such as SKF (Sweden), FAG (Germany), Koyo, NSK (Japan), SNR (France). Most often, in the production of mining equipment, in addition to the Russian 
ones, bearings of the Swedish company SKF and the Japanese company NSK are used [8, 9, $10]$. It should be noted that foreign companies account for up to $65 \%$ of bearings used in mining equipment.

In the production of mining equipment, all the main range of bearings (ball, roller, combined, needle) is used. Taking into account the specifics of operation (large static and shock loads) and the equipment design (large dimensions), large-size roller and ball bearings of various designs are mainly used [8].

In this work, the parts of bearings of the following three companies were investigated:

- a roller of a Russian-produced big bearing (Fig. 1, a);

- an NSK bearing inner and outer rings (Fig. 1, b);

- a roller of an $S K F$ big bearing (Fig. 1, c) $[11,12,13]$.

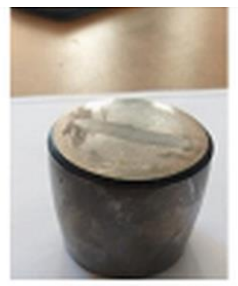

a)

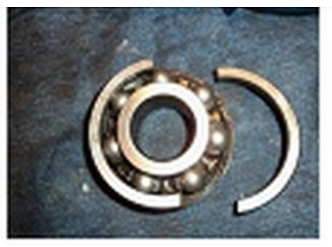

b)

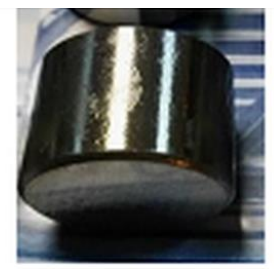

c)

Fig. 1. External View of the Investigated Elements of Rolling Contact Bearings:

a) a roller of a Russian-produced big bearing;

b) an NSK bearing inner and outer rings;

c) a roller of an $S K F$ big bearing.

The chemical composition of the steel was monitored, and the identification of the steel by grades was carried out. The quality of the metallurgical production of the steel in finished bearings was assessed by the microstructure - by the presence of cavities, non-metallic inclusions, carbide segregation, and segregation banding. The quality of heat treatment was determined by the hardness, as well as by the microstructure - the presence of the carbide network fragments was investigated, and the cellular structure size was determined.

\section{Discussion of Study Results}

The chemical composition of the investigated bearings steel of various manufacturers is given in Table 1, and the results of the study of the quality of bearing steel - in Table 2. It can be seen from the abovementioned Tables that the chemical composition meets the Russian standards and the requirements of foreign suppliers [7, 14].

Table 1. Chemical Composition of Bearings of Various Manufacturers

\begin{tabular}{|c|c|c|c|c|c|c|c|c|c|}
\hline & \multicolumn{9}{|c|}{ Mass fraction of elements, $\%$} \\
\hline $\begin{array}{c}\text { Steel } \\
\text { grades }\end{array}$ & 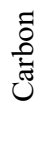 & $\stackrel{\Xi}{.0}$ & $\begin{array}{l}\text { ] } \\
\text { o. } \\
\stackrel{\Xi}{\Xi} \\
\sum\end{array}$ & $\stackrel{ }{U}$ & $\stackrel{\Xi}{\Xi}$ & $\begin{array}{l}\vec{D} \\
\frac{0}{0} \\
\frac{0}{0} \\
0 \\
\frac{1}{0}\end{array}$ & $\frac{\overline{0}}{\frac{y}{0}}$ & $\begin{array}{l}\dot{0} \\
\grave{0} \\
\dot{0}\end{array}$ & $\begin{array}{c}\text { Stand } \\
\text { ard }\end{array}$ \\
\hline
\end{tabular}




\begin{tabular}{|c|c|c|c|c|c|c|c|c|c|}
\hline & & & & & \multicolumn{6}{|c|}{} \\
\hline ShKh15SG & 1. & 0.53 & 0.9 & 1. & 0.00 & 0 & 0. & 0 & GOS \\
& 0 & 3 & 18 & 4 & 05 &. & 0 &. & T 801 \\
& 1 & & & 5 & & 0 & 4 & 0 & \\
& 5 & & & 7 & & 1 & 1 & 9 & \\
\hline SUJ2 & 0. & 0.22 & 0.3 & 1. & 0.00 & 0 & 0. & 0 & J \\
(ShKh15) & 9 & 3 & 36 & 5 & 05 &. & 0 &. & I \\
& 6 & & & 0 & & 0 & 6 & 0 & S \\
& 1 & & & 0 & & 1 & 9 & 7 & \\
& & & & & & & & 3 & \\
\hline 100cr6 & 0. & 0.19 & 0.2 & 1. & 0.00 & 0 & 0. & 0.0 & D \\
(ShKh15) & 8 & 3 & 92 & 4 & 07 &. & 0 & 66 & I \\
& 9 & & & 2 & & 0 & 1 & & N \\
& 0 & & & 4 & & 1 & 7 & & \\
\hline
\end{tabular}

Table 2. Results of Quality Control of Bearing Steel of Various Bearing Manufacturers

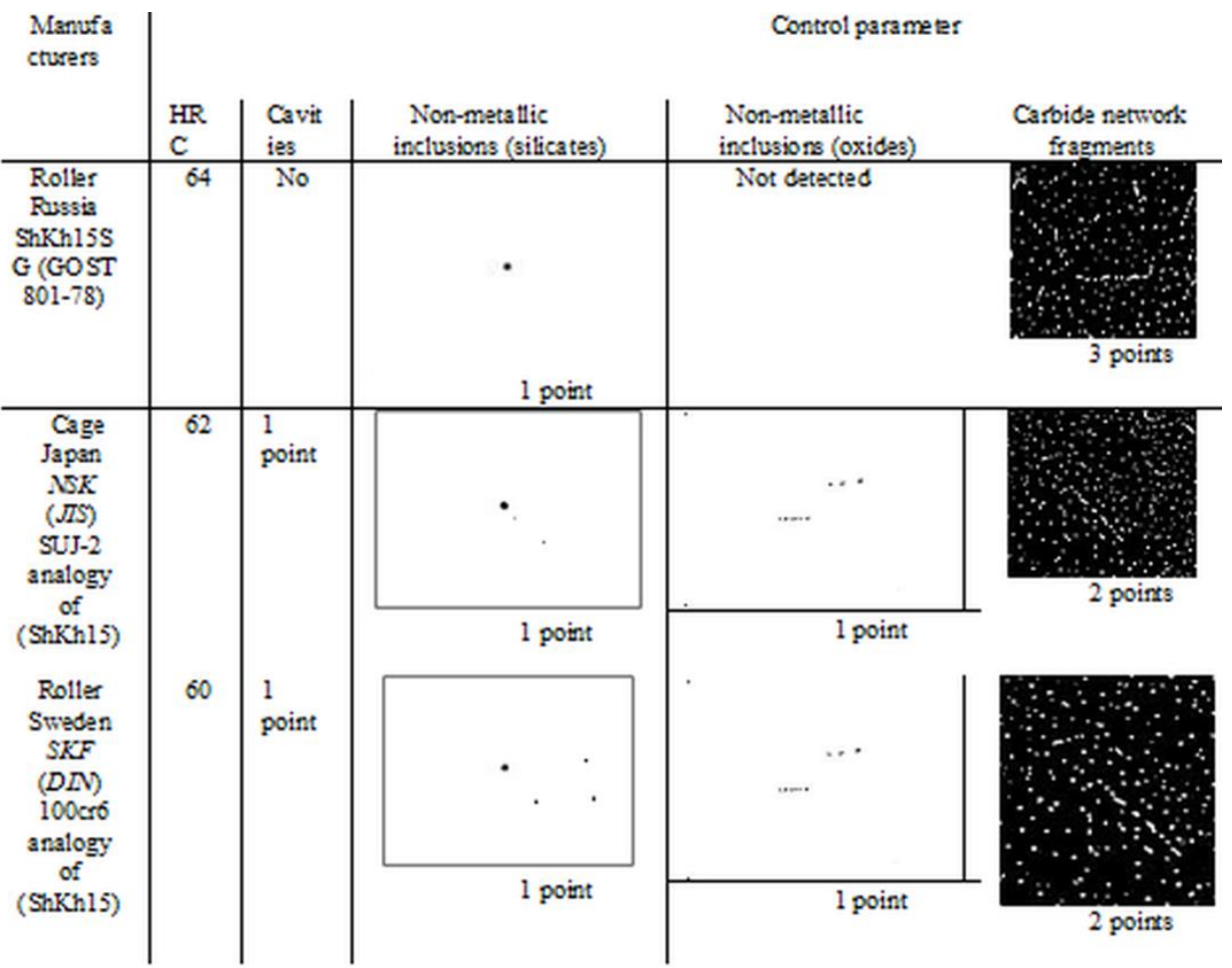

The hardness mainly meets the requirements of the standards (60-62 HRC). Only the SKF bearing shows a kind of the borderline case (60 HRC).

The results of metallographic studies also showed that the microstructure in the finished bearings met the standard requirements for the bearing steel of all three manufacturers. The microstructure parameters are different, but they are all within the permissible values, namely - non-metallic inclusions correspond to 1 point (with allowable 2 points), the fragments of the carbide network are in the range of 2-3 points (with allowable 3 points). 
The cavities were not found in the Russian product, but in SKF and NSK samples they are present and correspond to 1 point (with allowable 2 points). Additionally, the Russian manufacturer's bearing steel was investigated as delivered concerning the requirements of the standard (GOST 801).

Structural defects can occur at different technological stages of bearing manufacture. They can include defects both in metallurgical and blank production caused by heat treatment, mechanical treatment and grinding.

The steel quality at the stage of metallurgical production was assessed by the presence of non-metallic inclusions, microporosity, and structural banding; with subsequent preliminary heat treatment - by the presence of the decarburized layer, microstructure of lamellar pearlite, carbide segregation; after hardening heat treatment - by the presence of carbide network fragments. The quality of hardening heat treatment was assessed by hardness (not less than 62-64 HRC). Moreover, defects in the structure can be repairable and nonrepairable during subsequent operations [2].

The presence of microstructure defects in the bearing as delivered is dangerous at the stage of bearing production, since such defects lead to an increase in hardness up to 260-280 BH and, thereby, deteriorate technological properties, especially cutting ability and pressure machinability. These are repairable defects at the manufacturing stage, but it is important to detect them as delivered to prevent possible negative consequences.

The performance of finished bearings is significantly affected by microstructure defects, since they are inherited and lead to the deterioration in performance. Micro- and macrosegregation, porosity in the core, microstructure defects (carbide network, carbide segregation, decarburized layer), surface discontinuities of the metal (backfins, cracks, chaps, as well as forging, grinding, pickling cracks, clamp-offs, voids, shrinkholes, center and total porosity, gas bubbles, flakes) lead to various types of bearing destruction, such as surface shelling, splitting of bearings, surface potholes, pseudo brinelling, brinelling, abrasive wear.

The microstructure of the bearing steel of domestic manufacturers investigated in this work as delivered was represented by granular pearlite with secondary inclusions of carbides. Most often, it met the requirements of the standard and did not exceed the allowable 4 points in perlite grain size. The depth of the decarburized layer was predominantly in the range from 0.15 to $0.3 \mathrm{~mm}$, which corresponded to the permissible values. The hardness of the steel as delivered was in the range 179-207 $\mathrm{BH}$, after hardening treatment (localized hardening followed by low tempering) it made 62-64 HRC. The fragments of the carbide network did not exceed 3 points in most cases (see Table 3 ).

However, in the course of research, structural defects were found in the samples cut at the ends of the pipe.

It was found that in the metal of pipe workpieces made of ShKh15 bearing steel as delivered, deviations exceeded the permissible values (according to GOST 800), mainly in such parameters as pearlite microstructure (from 5 to 9 points), carbide network (up to 4 points), carbide segregation (up to 3-4 points), non-metallic inclusions (up to 3-4 points). Less common deviations in structural banding, chemical composition and deviations from the norm in the depth of the decarburized layer (less than $0.7 \mathrm{~mm}$ ) were also detected.

The presence of increased amount of non-metallic inclusions and cavities is a kind of fatal defects in metallurgical production. Inhomogeneity of the structure in the form of segregation banding, carbide segregation, carbide inhomogeneity is a defect of poorly performed hot pressure machinability - rolling. The presence of lamellar pearlite, coarse grains, and decarburized layer is a defect in preliminary heat treatment. The decarburized layer is removed by mechanical treatment. The fragments of lamellar pearlite above the allowable level (above 4 points) and fragments of carbide network above 3 points are removed by reheating. 
Defects of metallurgical production in the form of non-metallic inclusions and cavities were not found in the structure of all the studied samples of the domestic steel, which indicated the high quality of metallurgical production of the domestic bearing steel.

Studies of the bearing steel as delivered clearly demonstrated that in samples of the bearing steel with increased hardness, there were defects in metallurgical and blank production in the form of lamellar pearlite and carbide network. This leads to unsatisfactory technological properties, namely, to deterioration of cutting ability and pressure machinability in the cold state (see Table 3).

The relationship between microstructure, basic and technological properties in the bearing steel is shown.

The presented results demonstrate that the bearing steel structure contains defects that are inherited from previous technological operations in the finished bearing. These include carbide network, segregation, non-metallic inclusions (see Table 1).

In this work, the research was also carried out in order to choose a nondestructive control method for sorting bearings by metal quality in order to identify dangerous defects in the microstructure of finished bearings. For this, sound velocity method based on autocirculation of ultrasound pulses was chosen [15]. The tests were carried out on the Astron measuring and computing device (see Table 3).

The results of measurements on an acoustic device in the form of values of the autocirculation frequency of pulses of surface acoustic waves that passed through the area of the controlled metal, indicate the relationship of the speed of sound with the structure and the hardness of the bearing steel. The relative measurement of the pulse autocirculation frequency is directly proportional to the ultrasound speed, which is a structure-sensitive characteristic. Based on the results of the measurements (see Table 3 ), the threshold of the sound frequency between a defective and a defect-free metal was identified in the range of $8,898-8,870 \mathrm{kHz}$.

The conducted research can be used to assess the technological heredity in the quality control of the bearing steel in finished bearings using the sound velocity method.

The research results presented in Table 3 in the form of values of the frequency of pulses autocirculation of surface acoustic waves that passed through the area of the controlled metal, indicate the relationship of the speed of sound with the structure and the hardness of the bearing steel and can form the basis for the use of the method of nondestructive control to check the metal quality in finished bearings. 
Table 3. Influence of Steel ShKh15 Microstructure on Hardness and Speed of Ultrasound

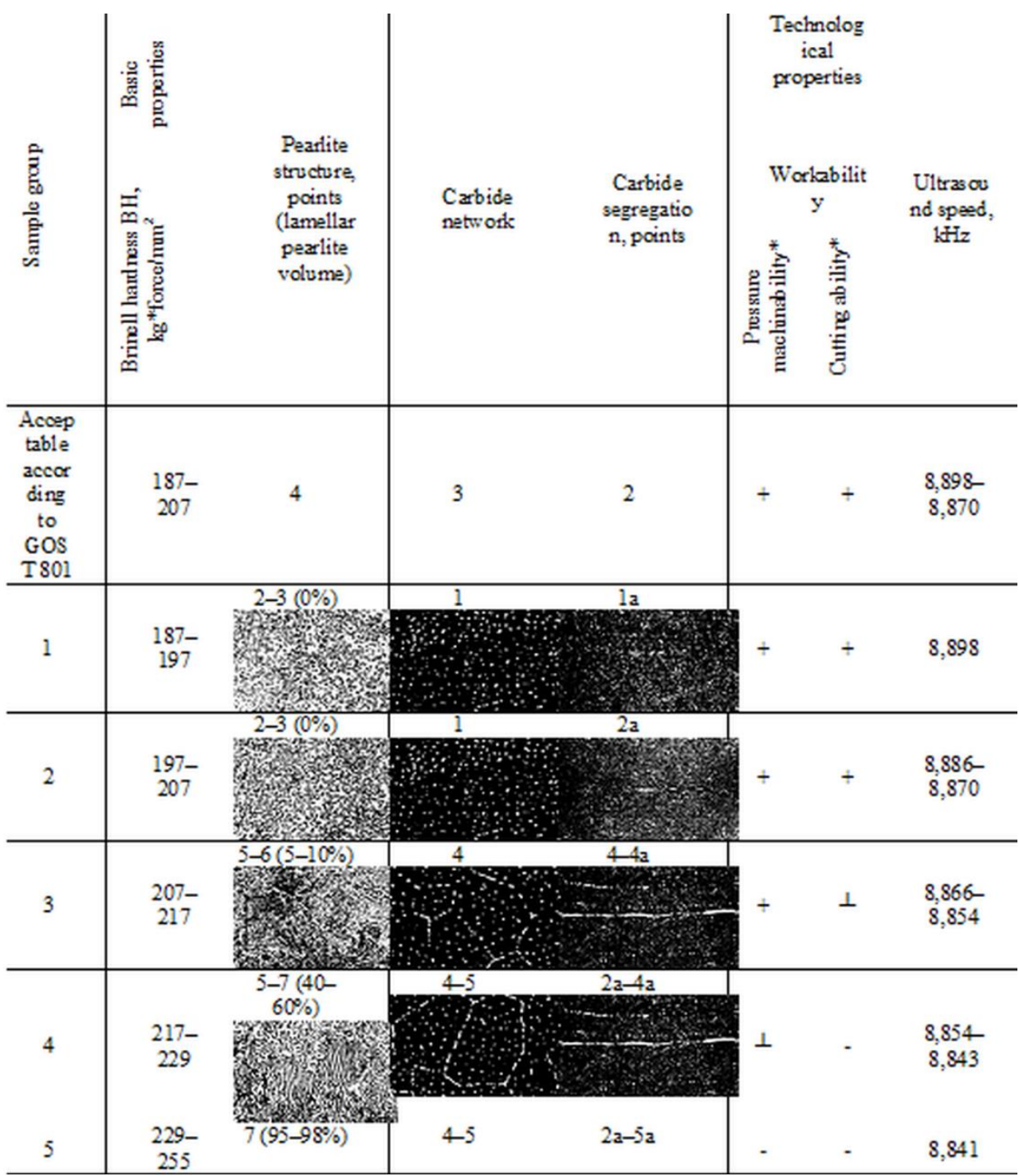

\section{Conclusion}

1. The state of the bearing industry market in Russia was examined. It was found that due to the intense competition, the domestic bearing production market was being replaced by foreign manufacturers;

2. A methodology for quality control of the bearing steel as delivered and after heat treatment based on technical requirements in accordance with GOST 801, was developed; the possible types of defects of the steel as delivered and after hardening heat treatment, as well as ways of their elimination were systematized;

3. The relationship among microstructure parameters, basic and technological properties 
of the steel was illustrated. The method of nondestructive control - supersonic survey - to detect the presence of inherited microstructure defects in finished bearings was chosen. The boundary of the ultrasound frequency between the permissible and unacceptable quality of the metal was established. It was also proposed, in addition to the existing control methods, to use the nondestructive method of supersonic survey to assess the steel quality of in finished rolling contact bearings;

4. Studies of the bearing steel quality were carried out based on the example of bearings from various manufacturers. It was found that domestic bearing steel as delivered complied with the standard (GOST 801). In terms of the quality of steels in finished bearings and in terms of structure and properties, domestic products were not inferior to foreign counterparts of production. Thus, the Russian-made bearings were proved to be competitive;

5. A method of acoustic nondestructive control was proposed in order to sort finished bearings according to the quality of the bearing steel.

\section{References}

1. S. Voeth, Maschinen Grundlagen der Elemente und Systeme Teill: Maschinenelemente (TH Georg Agricola, 2018)

2. N.D. Kosorukov, I.S. Solopin, S.Kh. Klorikyan, Machines and Equipment for Mines and Excavating Plants (Moscow State Mining University Publ., 2002)

3. W. Michael Washo, Bearings with Rolling Contact (McGraw-Hill, New York, San Francisco, Washington, D.C. et al., 1996)

4. V.A. Sidorov, Input Control of Rolling Contact Bearings( Vibration of Machines: Measurement, Reduction, Protection,2011)

5. M.I. Goldstein, S.V. Grachev, M.G. Veksler Spetsial'nyye stali: uchebnik dlya vuzov (Metallurgy ,Moscow, 1985)

6. N.V. Shakirov, XII All-Russian Scientific and Practical Conference of Young Scientists ('YOUNG RUSSIA' 2019)

7. Bearing Steel. Technical Conditions (Introduction.2004)

8. N.V. Shakirov XII All-Russian Scientific and Practical Conference of Young Scientists ('YOUNG RUSSIA', 2020)

9. O.V. Lyubimov Povysheniye resursa podshipnikovykh opor shnekovogo stava mashin gorizontal'nogo bureniya (Dissertation for Ph.D. Degree - Kemerovo, T.F. Gorbachev KuzSTU, 2012)

10. O.N. Chermenskiy, N.N. Fedotov. Podshipniki kacheniya : Spravochnik katalog (Mechanical Engineering, Moscow, 2003)

11. Official site of GPZ-1 Moscow plant for ball bearing production [Electronic resource] - Access mode: http://gpz1.ru/.

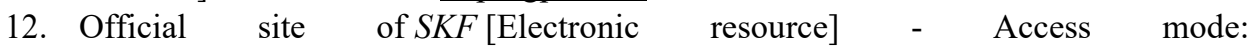
tps:/www.skf.com/ru/index.html.

13. Official site of NSK EUROPE LTD. [Electronic resource] - Access mode: https://www.nsk.com/index.html.

14. Klyuch k stalyam: Spravochnik (Profession Publ, St. Petersburg, 2006 )

15. A.N. Smirnov, V.V. Muravyov, N.V. Ababkov,Innovative Mechanical Engineering, 2016 